\title{
Forum
}

\section{Classics for the Future: A Time for Reflection}

\author{
David Hodgkinson \\ Independent Scholar
}

Key words: Classics, Future, Pedagogy, Direction, Education

Classics as a discipline was the bedrock of an elite education in the UK for some time. To some minds, it still holds on to that position, not least because there is a certain mystique and aura around the two dominant languages of early Europe and their literature. The discipline of learning these languages, so the argument went, could improve our ability to analyse questions, and think about our own language, thereby increasing our potential in future life. This sort of intellectual exercise was said to be valuable: by learning a language which we could not actually use in day-to-day life, we could also learn other, modern languages more effectively, and we could sharpen our minds to face the challenges of the world in front of us.

Such an argument, though, has considerable weaknesses, not least as such an education is only available to a privileged few, and the energy and effort required to read these languages at a reasonable level are considerable. Only a very few will get there, not only because of their natural linguistic abilities, but also because of financial constraints. The benefits of sharpening the mind would also apply to those learning German, Hindi or Arabic. We need, therefore, to reconsider the role of Classics - and most especially Latin and Greek - in a $21^{\text {st }}$ Century education. In simple terms, faced with an ever-increasing emphasis in the popular educational mind on STEM subjects, if we do not come up with something better, the wider forces in the education world will see to it that this subject dwindles to a point where it is nothing more than a nice asset to have for those who would like to look clever. Such a luxury is of questionable benefit in a world which is beset with serious social, economic and, above all, ecological challenges. Is there, therefore, a different vision for the subject which is both practical and educationally beneficial to the nation as a whole?

Education is a preparation for life, socially, psychologically and economically. As we go into a yet more technological age, the power at people's fingertips is ever increasing. Today, it is possible to broadcast a message to the world within seconds, as the former President of the United States' Twitter feed has shown. We are also able to use technology to do many of the jobs previously done by people, and this will be an ever-increasing trend. Linguists may well find themselves out of jobs, as AI takes over the role of interpreting and translating documents and press conferences; automation will

Author of correspondence: David Hodgkinson, E-mail: dls.hodgkinson@ntlworld.com Cite this article: Hodgkinson D (2021). Classics for the Future: A Time for Reflection. Journal of Classics Teaching, 22, 106-108. https://doi.org/10.1017/S2058631021000234 ensure that many of the more physical aspects of life happen without the need for large numbers of people. Even highly skilled surgeons may find themselves competing with robots. The direction of travel is clear, provided the planet can sustain it. Whilst these considerable advances may come at a cost with a marked need to re-evaluate the workings of our society, they can also be regarded as offering opportunities, which raise questions about our values and how we treat one another. In such a world, what role does education play?

The study of Latin and Greek challenges us to think about communication and thought. We are deciphering texts whose authors cannot speak to us directly, but whose thought was every bit as sharp and meaningful as our own. Such a process works on two levels: the basic questions of grammar, morphology and syntax are challenging enough, and sharpen our wits. As we consider literature at both GCSE and A Level, we turn to thinking about style and word order. All this adds up to thinking about and developing our understanding of how humans communicate with one another. The Italian notion that 'translators are traitors' plays its part here. We are always left with a simple question: what is translation? How do we convey the same meaning to a speaker of another language as we convey to a speaker of our own language. The disadvantage of ancient languages is also their strength: we can think about these questions without insulting others and without there being a definitive answer: we consider how meaning is constructed, and how we can convey that meaning in English. This, one would hope, would help us to communicate more effectively in the world. Such a line of argument is traditional, but it still requires us to focus on both the process of translating and the next step, which is the construction of meaning in real life. It is not just an intellectual abstraction with a correct answer. It is something which can, from the very first day of Latin, be considered and discussed by asking simple questions: what difference does it make that there is no definite article in Latin, or that we cannot distinguish between 'I walk' and 'I am walking' in the language? Such questions enable students to refine their English, but we must take time to consider these points, and look for opportunities to discuss them (for further discussion, see Found 2017 and Praet \& Verhelst 2020).

The ancient world can offer us opportunities to reflect on our own lives, on the human condition and on the mistakes which people have made in the past. Thucydides observed that, human nature being what it was, events would repeat themselves. Such an 
observation is particularly pertinent in relation to studying the past. The emotions of greed, anger and jealousy, so eloquently expounded by Horace in his Satires, have not left us, and continue to wreak havoc across the globe: by reading such a text, we can reflect and learn from it. At first, Horace's words may seem obscure, but good teaching can use a text as a starting point, and draw out lively debate from students of almost any age. On occasion, we may profoundly disagree with the viewpoint of an ancient author, but we can also learn from it.

Recent months have rightly seen a greater focus in everyone's minds on questions of racism and embedded discrimination in society. The language of opportunity and meritocracy is no longer enough: action is needed, and such action needs to ensure that the words and actions match. The distinction so clearly expressed between word (logos) and action (ergon) in fifth century Athenian discourse can again help us to reflect on a simple question: do we do what we say? Issues of race and equality also come to the fore when we reflect on ancient societies: Plato's philosopher rulers may appear an intelligent solution to the ills of our society, and the great achievements of the Periclean building programme are worthy of our attention, but we also need to consider the cost at which they came: slavery, war and the subjugation of others. Such themes find themselves poetically expressed in Vergil's Aeneid and Eclogues. They are, however, not just historical issues to be examined in the test tube of intellectual debate: they are real issues which affect all of us, and require us each to consider our own behaviour and role in society. In short, at school level, we need to start to use these Classics as a starting point for wider reflection, not just as something 'about the past'. The current examination system consistently drives us in another direction, and does little to support or encourage students to explore more widely.

Herodotus has much to teach us about other people. This is not so much about the ethnography and veracity of his accounts of others, but his approach. His own background in Halicarnassus led him to meet people from both the Greek and non-Greek worlds, with the result that he showed a degree of open-mindedness which often appears to be lacking in fifth century Athenian discourse. This spirit, combined with the archaeological evidence of the influence of sculpture in Persepolis on Athenian sculpture, can show how the rhetoric of the barbarian is just that: a rhetoric. Such rhetoric, though, can be believed. By studying the two we can begin to open our eyes to how to treat others, and recognise that, in the words of Pindar quoted by Herodotus, 'Custom (nomos) is the king of all'. Using the examples given by Herodotus, and then reflecting on such examples can help us today to open our minds to others, and reflect on the limitations and strengths of our own cultures.

Within society, women in the Greco-Roman world were not party to the political processes and decision-making as they are today. Any such involvement was held as either comic or deeply suspicious, as Aristophanes, Suetonius and Tacitus attest. Such attitudes were, however, not held by all: some Celtic societies saw things very differently, as Boudicca's role with the Iceni demonstrates. The suspicion with which women were treated, as shown also by the persistent myth of the Amazons, again offers an opportunity to reflect. We can consider why such attitudes might have been held, and think about why the roles of man and woman were seen as so different. We can also reflect on how we value the traditionally female role of the carer in our society, and use the ancient world as a starting point to consider the way forward for our societies.

In a world where technology is ever advancing, ethics will become increasingly important. How we think, and how we act towards others, will be key. Here, the Classical World has much to teach us. We can examine the role slavery played in that world, and learn from this. We can also examine the concepts from the ancient world, such as arete or virtus, and consider what they say to us today: they have inherent limitations, not least in relation to questions of gender and identity, but also much that is positive to offer. The exploration of such ideas can be used to foster debate and a consideration of key questions which will help to shape the thinking and the ability to think of the next generation.

Ethical issues are often at the heart of questions in GrecoRoman mythology, history and literature. Vergil's Aeneid, for example, raises questions about the ethics of conquest, and the effects of conquest on others. Caesar's Gallic Wars leaves great questions unanswered about how to treat foreigners and the nature of profits from such wars. These are all questions which are pertinent to today, just as they were two millennia ago, and questions which can be considered in a more nuanced way if one can look at the original text, and understand something of the words and phrasing used.

How the human race is to organise itself, and be governed is also a pressing question. In the West, we praise democracy, but there are clear existential threats to that form of government which are, in part, down to its own success. The philosophical arguments in Plato's Republic raise significant issues about how we should be governed, and the nature of the rulers in our society. Here again the text provides a starting point, and a knowledge of language can help to refine our debate, and move away from fixed ideas about concepts and ideas, such as aristocracy. To encourage the next generation to think carefully about government and the consequences of particular forms of government would be a valuable element of education which Classics could offer.

Texts such as Aristotle's Nicomachaean Ethics also offer us an opportunity to consider our approach to life and our values. His teleological approach to human life raises questions for us, which we can debate and which can help our pupils to reflect on their own lives and priorities. The text as a whole may be difficult, but the essential ideas drawn from it, such as the Golden Mean, are excellent ways to explore behaviour. To use some Greek in such discussions to assist in elucidating key ideas can again help to stimulate debate on highly significant questions in our lives. Equally, Plato's notion of the harmony of the parts of the soul and each part doing what is appropriate for itself makes an excellent starting point for discussing how to live, and how to satisfy the various needs which we all feel.

The rise of science and technology also means that a host of technical terms which are used daily by those working in these fields have become ever more important. Such words, especially in Chemistry and Medicine, are often Greek. Words such as allotrope or stoichiometry describe concepts, which are held in the words themselves, and which can be unlocked with appropriate knowledge of Greek. Likewise in medicine, a little knowledge of the right Greek could go a long way: hypoglycaemia and hyperglycaemia need rather different treatment, as does a patient who is now apyretic. If the curriculum were constructed appropriately, students who had studied Greek could find themselves with an advantage in future life, but could also have had an interesting time making connections with a wide range of different subjects.

It goes without saying that one of the greatest challenges of our age is caring for the environment. Here again, the ancient world has much to teach. We have moved on from believing in Poseidon and Artemis, but the forces for which they stood remain with us. 
The struggles of Odysseus with the sea remind us that the sea is a powerful force. Global warming and melting ice-caps may show us all too soon how powerful they are. Ancient literature and culture is suffused with deities whose presence reminds us of the natural world around us - a natural world which we are in danger of taking for granted. We do not have to believe in these deities to use their presence in the ancient world as a starting point for debate: depictions of Artemis or Demeter and Persephone can remind us of the cycles of nature, and lead us to discover how we too might respect them. The respect is the starting point; the solutions may well be very different.

This article is a call for us to use learning about the ancient world as an opportunity to learn about the world around us. On the level of language, we can see how we construct meaning, and how we can use language to improve our society. In relation to culture, we can use the observations of our forebears to provoke discussion about how we would like to behave. We can see the consequences of their actions, and the limitations of their viewpoints, as an opportunity to avoid making such mistakes ourselves. The distance provided by the millennia which separate us from them enables such discussion to be full, open and frank without insulting others. Classics could be at the heart of education: it could enable the next generation to reflect on the future direction, not only of their own lives, but also of our race.

In short, for Classics to survive and thrive, it needs to have meaning. At present, it has this for a limited few who are either drawn by intellectual curiosity to the languages or by the spectre of the myths which are so loved by children (and adults). Such things provide entertainment. They, and other elements of the ancient world, could also provide opportunities for reflection and a deepening of our understanding of the world around us, both linguistic and scientific, our values and how we live. To do this, however, we have to be willing to move into an area which cannot simply be assessed through narrow assessment objectives, and acknowledge that true education is more than the learning of facts and jumping through artificially defined hoops. It involves encouraging others to think, and to have ideas of their own which might, one day, change the world, ideally for the better.

\section{References}

Found P (2017) Translation or Adaptation? Journal of Classics Teaching 18, 8-10. Praet S and Verhelst B (2020) Teaching Translation Theory and Practice. Journal of Classics Teaching 21, 31-35. 